\title{
Integrative and Complementary Practices to Control Nausea and Vomiting in Pregnant Women: A Systematic Review Protocol
}

Melissa Santos Nassif ( $\square$ melissasantosnassif@hotmail.com )

Universidade Federal de Alfenas Alfenas https://orcid.org/0000-0003-0323-004X

Isabelle Cristinne Pinto Costa

Universidade Federal de Alfenas

Caroline de Castro Moura

Universidade Federal de Vicosa

Patrícia Mônica Ribeiro

Universidade Federal de Alfenas

\section{Protocol}

Keywords: Complementary Therapies, Pregnancy, Systematic Review

Posted Date: June 1st, 2021

DOl: https://doi.org/10.21203/rs.3.rs-528905/v1

License: (c) (i) This work is licensed under a Creative Commons Attribution 4.0 International License. Read Full License 


\section{Abstract}

\section{Background}

The stages of pregnancy are accompanied by several biopsychosocial changes, among them are nausea and vomiting, which are often associated with negative feelings, in addition to generating physical impacts and impacts on the maternal quality of life. In this scenario, the Integrative and Complementary Practices (ICPs) are inserted as a potential treatment to control nausea and vomiting in this public. This review aims to synthesize the available evidence in the literature on the effects of integrative and complementary practices in the treatment of nausea and vomiting in pregnant women.

Method

The review will include only randomized controlled trials (RCTs) that examine the effects of ICPs versus placebo, routine treatment, or pharmacological intervention for the control of nausea and vomiting in healthy pregnant women. The outcomes of interest are those related to nausea and vomiting and possible adverse effects of the intervention. A search for studies will be carried out in the following databases: MEDLINE via PubMed, EMBASE, CINAHL, CENTRAL, ICTRP, LILACS, CUMED, IBECS, Web of Science, Scopus, CNKI, the World Health Organization's International Clinical Trials Registry Platform (ICTRP) and ReBEC until July 31, 2021. There will be no restrictions on the publication year or language of the manuscripts. The texts will be evaluated in their entirety, after which they will be selected, the data of interest will be extracted, and the risk of bias and quality of evidence will be evaluated. The entire selection process will be carried out by two independent reviewers and a third reviewer will be available in case of disagreement. In the event that a meta-analysis can be conducted, it will evaluate interventions for the absolute difference between averages and potential heterogeneity. If the data are deemed inadequate for a meta-analysis, a systematic narrative synthesis will be carried out. This protocol was proposed based on the preferred reporting item guidelines for systematic review and meta-analysis protocols (PRISMA-P).

\section{Discussion}

The results of this systematic review will robustly fill this knowledge gap and possibly assist in evidencebased practices provided for pregnant women experiencing nausea and vomiting.

Systematic review registration: PROSPERO CRD42020221570

\section{Introduction}

The stages of pregnancy are accompanied by several biopsychosocial changes, which impact the lives of pregnant women and their families in different ways. Nausea and vomiting affect $50-80 \%$ of women during pregnancy $(1,2,3,4)$, and is considered a physiological alteration that normally occurs between the sixth and twelfth weeks of pregnancy (5). Its origin is not well known, and it is most likely linked to the 
hormonal, anatomical, and immunological changes of pregnancy (5). It may assume a more severe and prolonged form, named hyperemesis gravidarum $(\mathrm{HG})$, which is characterized by persistent vomiting that leads to weight loss and hydro-electrolytic imbalance (6).

Although nausea and vomiting during pregnancy are not considered a pathology, these symptoms are often associated with feelings of inadequacy, depression, anxiety, and maternal stress $(7,8)$. Moreover, they are major causes of absence from work (7), as well as being causes that affect patients' physical functions, quality of life, and family and social relationships $(2,9,10)$.

Therefore, effective interventions are essential, where traditional treatment is prevalently based on dietary changes and antinauseant, antiemetic, and antihistamine medications $(5,11)$. However, patients may be reluctant to use such medications, since these medications have been associated with some side effects, such as dry mouth, constipation, restlessness, drowsiness, peptic ulcer, or arrhythmia $(12,13)$. Added to this is the desire pregnant women have to have control over their health and preserve it in a holistic manner (14) since the great majority of this population states that they are afraid of the possible teratogenic effects associated with the repetitive use of drugs during pregnancy (15).

In this scenario, the Integrative and Complementary Practices (ICPs) stand out, which focus on a holistic, individualized, and integrated care model that reduces the dependence on medication and healthcare services (5). The ICPs have been frequently used during pregnancy, as pointed out by a survey that sought to map the prevalence of this use, identifying that $45 \%$ (16) of pregnant women used some type of ICP, and the most commonly requested were acupuncture $46 \%$ (17) and phytotherapy (71.3\%) (18).

Currently, there are numerous studies that verify the application of various types of ICPs in the pregnancy setting. Observing systematic reviews from the last five years, it is noted that aromatherapy with lemon significantly impacted the control of nausea and vomiting during pregnancy (19); hypnotherapy proved effective for improving pregnant women's expectations and emotional experiences of childbirth (20); homeopathy and phytotherapy were tested for safety of use during pregnancy (21); acupuncture has shown efficacy in managing insomnia during pregnancy (22); auricular acupuncture was effective for treating pregnancy-related lumbar pain compared with placebo (23); music therapy was able to significantly reduce gestational anxiety (24); yoga was effective in reducing depression and anxiety symptoms in pregnant women (25).

Considering that a high number of pregnant women are affected by nausea and vomiting and that they have prioritized the use of ICPs over medications, in addition to the research results that point to several ICPs as a potential treatment to manage nausea and vomiting in this public, and that there is no robust literature review regarding the available evidence on these treatments, the objectives of this review are:

1. To synthesize the available evidence in the literature on the effects of integrative and complementary practices in the treatment of nausea and vomiting in pregnant women.

2. To identify the possible adverse effects associated with the use of integrative and complementary practices in the treatment of nausea and vomiting in pregnant women. 
3. To elaborate a possible set of Core Outcome Sets (COS) focused on the management of nausea and vomiting in pregnant women.

\section{Method}

\section{Protocol and registration}

The protocol for this systematic review is registered in the International Prospective Register of Systematic Reviews (PROSPERO) CRD42020221570.

\section{Research Question Development}

This research protocol is reported according to the Preferred Reporting Items for Systematic Review and Meta-Analysis Protocols (PRISMA-P 2015). The PICO strategy (P- population; I- intervention; Ccomparison; 0- outcomes) guided the research question (26) (Table 1).

Table 1

Research question development

\begin{tabular}{|ll|}
\hline PICO & COMPONENTS \\
\hline $\begin{array}{l}\text { Research } \\
\text { question }\end{array}$ & $\begin{array}{l}\text { Are integrative and complementary practices effective in managing nausea and } \\
\text { vomiting in pregnant women compared to placebo, routine treatment, or } \\
\text { pharmacological interventions? }\end{array}$ \\
\hline Population & Pregnant women with symptoms of nausea and vomiting. \\
\hline Intervention & Integrative and complementary practices.* \\
\hline Comparison & Placebo, routine treatment, and pharmacological interventions. \\
\hline Outcomes & Management of nausea and vomiting, and adverse effects from the treatment. \\
\hline *Specified under the topic: Intervention Types and Comparison \\
\hline
\end{tabular}

\section{Eligibility Criteria}

\section{Types of Research}

Only randomized clinical trials on the use of complementary therapies to manage nausea and vomiting in pregnant women will be included.

\section{Types of Participants}

Healthy pregnant women of any gestational age (GA), who are experiencing nausea and vomiting. Parturient and puerperal women will be excluded. Papers involving symptoms characterized as hyperemesis gravidarum will not be included, since these diverge from the population of interest in this 
study, which represents $1 \%$ of pregnant women who have developed the pathological form of gestational nausea and vomiting (6). There will be no age or ethnicity limitations.

\section{Types of Intervention and Comparison}

Studies that aimed to manage nausea and vomiting in pregnant women by employing aromatherapy (19), hypnotherapy (20), homeopathy (21), acupuncture (22), auricular acupuncture (23), music therapy (24), phytotherapy (21), and yoga (25) will be analyzed. The use of these ICPs is justified due to their frequent use in the obstetric setting, in addition to the previous concept of their efficacy with pregnant women from current systematic reviews, even if for other study purposes. The intervention may have been used alone or as an adjuvant to other methods.

Management interventions may include: (a) any placebo method (specific to each ICP); (b) vitamin B6 alone or in combination with doxylamine, which is considered the gold standard in managing nausea and vomiting in gestation (27); (c) other pharmacological interventions; (d) other non-pharmacological interventions.

\section{Types of Results}

The primary results to be evaluated will be nausea and vomiting in pregnant women at any gestational age. The secondary results to be evaluated will be possible adverse events arising from the use of these complementary therapies to manage nausea and vomiting in pregnant women.

It should be noted that there is currently no set COS for clinical trials in which the effects of interventions to manage nausea and vomiting in pregnant women are studied, therefore, all the instruments proposed by the included studies will be evaluated.

\section{Information Sources}

The search for studies will be carried out in the following databases: Medical Literature Analysis and Retrieval System Online (Medline) via PubMed, EMBASE (via Embase.com), Cumulative Index to Nursing and Allied Health Literature (CINAHL), Cochrane Central Register of Controlled Trials (CENTRAL), Web of Science, Scopus, the World Health Organization's International Clinical Trials Registry Platform (ICTRP), Literatura Latino-Americana em Ciências da Saúde (LILACS), Cuban National Center for Information on Medical Sciences (CUMED), Índice Bibliográfico Español en Ciencias de la Salud (IBECS), China National Knowledge Infrastructure (CNKI).

There will be no restrictions on the publication year or language of the manuscripts. For each article selected, abstracts and full articles will be obtained. Aiming to increase the literature coverage, reference lists of included studies and systematic reviews identified during the screening process will also be examined. In addition, papers from the gray literature will be captured and ongoing studies will be identified through the World Health Organization's International Clinical Trials Registry Platform, and the Brazilian Registry of Clinical Trials (ReBEC).

\section{Search Strategy}


Table 2 - Descriptors for the search strategy

\begin{tabular}{|c|c|c|}
\hline \multicolumn{3}{|c|}{ A. Search strategy to search for "Integrative and Complementary Therapies": } \\
\hline 1. & Terapias complementares & 1. Complementary Therapies \\
\hline 2. & Medicina Complementar & 2. Alternative Therapies \\
\hline 3. & Medicina Integrativa e Complementar & 3. Complementary Medicine \\
\hline 4. & Práticas Integrativas e Complementares & 4. Medicine, Alternative \\
\hline 5. & Aromaterapia & 5. Aromatherapy \\
\hline 6. & Hipnoterapia & 6. Hypnosis \\
\hline 7. & Homeopatia & 7. Homeopathy \\
\hline 8. & Acupuntura & 8. Acupuncture \\
\hline 9. & Acupuntura Auricular & 9. Acupuncture, Ear \\
\hline 10. & Musicoterapia & 10. Music Therapy \\
\hline 11. & Fitoterapia & 11. Phytotherapy \\
\hline 12. & loga & 12. Medicine, Herbal \\
\hline & & 13. Yoga \\
\hline \multicolumn{3}{|c|}{ B. Search strategy to search for "Nausea and Vomiting": } \\
\hline 1. & Náusea & 1. Nausea \\
\hline 2. & Ânsia de Vômito & 2. Vomiting \\
\hline 3. & Enjoo & 3. Emesis \\
\hline 4. & Náuseas & 4. Morning Sickness \\
\hline 5. & Vômito & \\
\hline 6. & Êmese & \\
\hline 7. & Êmese Gravídica & \\
\hline 8. & Enjoo do Começo da Gravidez & \\
\hline & Náuseas e Vômitos Matinais da Gravidez & \\
\hline 10. & Náuseas e Vômitos da Gravidez & \\
\hline C. & Search strategy to search for "Pregnant": & \\
\hline 1. & Gravidez & 1. Pregnancy \\
\hline 2. & Gestação & 2. Gestation \\
\hline
\end{tabular}


Chart 1 - Search strategies 


\begin{tabular}{|c|c|c|}
\hline Database & $\begin{array}{l}\text { Descriptor } \\
\text { system }\end{array}$ & Search Strategy \\
\hline \multirow[t]{4}{*}{$\begin{array}{l}\text { LILACS } \\
\text { CUMED } \\
\text { IBECS }\end{array}$} & \multirow[t]{4}{*}{ DeCS } & $\begin{array}{l}\text { (Terapias Complementares) OR (Medicina Complementar) OR (Medicina } \\
\text { Integrativa e Complementar) OR (Práticas Integrativas e Complementares) } \\
\text { AND (Náusea) OR (Ânsia de Vômito) OR (Enjoo) OR (Náuseas) AND } \\
\text { (Gravidez) OR (Gestação) }\end{array}$ \\
\hline & & $\begin{array}{l}\text { (Terapias Complementares) OR (Medicina Complementar) OR (Medicina } \\
\text { Integrativa e Complementar) OR (Práticas Integrativas e Complementares) } \\
\text { AND (Vômito) OR (Êmese) AND (Gravidez) OR (Gestação) }\end{array}$ \\
\hline & & $\begin{array}{l}\text { (Terapias Complementares) OR (Medicina Complementar) OR (Medicina } \\
\text { Integrativa e Complementar) OR (Práticas Integrativas e Complementares) } \\
\text { AND (Êmese Gravídica) OR (Enjoo do Começo da Gravidez) OR (Náuseas e } \\
\text { Vômitos Matinais da Gravidez) OR (Náuseas e Vômitos da Gravidez) }\end{array}$ \\
\hline & & $\begin{array}{l}\text { (Terapias Complementares) OR (Medicina Complementar) OR (Medicina } \\
\text { Integrativa e Complementar) OR (Práticas Integrativas e Complementares) } \\
\text { AND (Aromaterapia) OR (Hipnose) OR (Homeopatia) OR (Acupuntura) OR } \\
\text { (Acupuntura Auricular) OR (Musicoterapia) OR (Fitoterapia) OR (loga) AND } \\
\text { (Gravidez) OR (Gestação) }\end{array}$ \\
\hline \multirow{3}{*}{$\begin{array}{l}\text { Medline } \\
\text { Web of } \\
\text { Science } \\
\text { Scopus }\end{array}$} & \multirow[t]{6}{*}{$\mathrm{MeSH}$} & (Complementary Therapies) OR (Alternative Therapies) OR \\
\hline & & (Pregnancy) OR (Gestation) \\
\hline & & (Complementary Therapies) OR (Alternative Therapies) OR \\
\hline \multirow{3}{*}{$\begin{array}{l}\text { ICTRP } \\
\text { CENTRAL } \\
\text { CNKI }\end{array}$} & & (Emesis) AND (Pregnancy) OR (Gestation) \\
\hline & & $\begin{array}{l}\text { (Complementary Therapies) OR (Alternative Therapies) OR } \\
\text { (Complementary Medicine) OR (Medicine, Alternative) AND (Morning } \\
\text { Sickness) }\end{array}$ \\
\hline & & $\begin{array}{l}\text { (Complementary Therapies) OR (Alternative Therapies) OR } \\
\text { Complementary Medicine) OR (Medicine, Alternative) AND } \\
\text { (Aromatherapy) OR (Hypnosis) (Homeopathy) OR (Acupuncture) OR } \\
\text { (Acupuncture, Ear) OR (Music Therapy) OR (Phytotherapy) OR (Yoga) AND } \\
\text { (Pregnancy) OR (Gestation) }\end{array}$ \\
\hline \multirow[t]{3}{*}{ CINAHL } & \multirow{3}{*}{$\begin{array}{l}\text { Termo } \\
\text { CINAHL }\end{array}$} & (Alternative Therapies) AND (Nausea) AND (Pregnancy) \\
\hline & & (Alternative Therapies) AND (Vomiting) AND (Pregnancy) \\
\hline & & $\begin{array}{l}\text { (Alternative Therapies) AND (Aromatherapy) OR (Hypnosis) OR } \\
\text { (Homeopathy) OR (Acupuncture) OR (Acupuncture, Ear) OR (Music } \\
\text { Therapy) OR (Medicine, Herbal) OR (Yoga) AND (Pregnancy) }\end{array}$ \\
\hline \multirow[t]{3}{*}{ EMBASE } & \multirow{3}{*}{$\begin{array}{l}\text { Emtree } \\
\text { Tesouros }\end{array}$} & (Alternative Therapies) AND (Nausea) AND (Pregnancy) \\
\hline & & (Alternative Therapies) AND (Vomiting) AND (Pregnancy) \\
\hline & & $\begin{array}{l}\text { (Alternative Therapies) AND (Aromatherapy) OR (Hypnosis) OR } \\
\text { (Homeopathy) OR (Acupuncture) OR (Auricular Acupuncture) OR (Music } \\
\text { Therapy) OR (Naturopathy) OR (Phytotherapy) OR (Yoga) AND } \\
\text { (Pregnancy) }\end{array}$ \\
\hline
\end{tabular}


The search will be carried out in the aforementioned databases and then loaded into the EndNote® reference manager, which allows the organization of references identified in different electronic databases. All results will be entered into this manager and duplicate studies will be identified and removed. Then, this database will be exported to the Rayyan ${ }^{\circledR}$ software, where the selection process of the studies will take place since this tool allows the articles to be mined by independent reviewers with the option of blinding amongst them.

\section{Selection Process}

All articles will be selected by two different reviewers in a blinded approach, and at the end, any disagreements will be settled by a third researcher after mutual discussion. The article selection process will be carried out in three stages. The first is the title reading, in an attempt to find the keywords that indicate the use of some type of ICPs in pregnant women. The second stage involves reading the abstracts, attempting to filter out whether the studies focused on nausea and vomiting management. Finally, in the third stage, the pre-selected articles will be read in their entirety and checked against the predefined eligibility criteria. The entire process of searching, screening, and selecting studies will be presented using the PRISMA flow chart.

\section{Data Extraction}

Data collection will be carried out after the study selection process, using a data extraction form, which will be adapted for this review, based on the data extraction and evaluation model proposed by the Cochrane Handbook for Systematic Reviews of Interventions (26). Training on how to fill out the form will be proposed. In addition, the forms will be reviewed and discussed by the authors, based on the extraction of data by everyone, individually from a study, which will be compared in order to unify the understanding of each topic and minimize inconsistencies.

Two authors will be involved in the data extraction process of each one of the selected studies, for the aforementioned form, individually. Another reviewer will be responsible for cross-referencing this information. In case of contradiction between the data, the two authors who carried out the extraction will discuss it; if there is no common agreement, a third author will analyze it and provide the final opinion.

If the data presentation is incomplete, the corresponding authors of the research will be contacted by email (maximum of three attempts) to complement the information.

The data extraction form will be based on the identification, design, and methods of the study and information will be collected regarding the participants, intervention, outcome measures used, and results (28) ( Chart 2).

Chart 2 - Data extraction form items 


\section{Identification First author, title, year of publication, journal, country.}

Eligibility Confirm eligibility for review

Introduction Study objectives and included hypotheses

Method - Study design, allocation and concealment technique, randomization, blinding and design and masking.

group

allocation

Method - $\quad$ Age, race, Gestational Age, eligibility criteria.

Participants

Method - $\quad$ Duration, ICP used, treatment protocol, comparison group, control group.

Interventions

Method - Statistical analyses used.

Statistical

Analysis

Results Sociodemographic data, number of participants randomized/allocated per group/analyzed, sample losses, summary data for each group at each time point, intervention compliance, frequency and duration of nausea and vomiting, adverse effects, quality of life, what tools were used for assessment, and other pertinent variables.

Discussion Interpretation of results and main conclusions.

\section{Risk of Bias}

It is believed that the quality of a study is inversely proportional to its risk of bias. The eligible articles will be assessed for their methodological quality by using the Cochrane Risk of Bias Tool ROB2 (29). With this tool, it is possible to assess each study's risk of bias in six different domains. These domains are as follows: randomization process, intervention attribution, incomplete data on outcomes, measurement of results, selective reporting of outcomes, and general risk of bias.

For each of these domains, the risk of bias will be classified as follows: high, uncertain, or low, therefore enabling the visibility of the reliability of the results of the analyzed studies. This evaluation will be carried out by two independent authors and a third author will be consulted to solve possible divergences.

\section{Data Synthesis and Analysis}

If meta-analysis can be carried out, the statistical software Stata SE/12.0 will be used for data analysis. The absolute difference between means, with $95 \%$ confidence intervals, will be selected to describe the mean differences between the treated and control groups at the evaluation performed immediately after the treatment completion. A p-value of $<0.05$ will be considered statistically significant.

The potential heterogeneity among studies will be examined using Cochran's Q statistics (30) and Higgins' method ( $\mathrm{I}^{2}$ statistics), (31). Values of $25 \%, 50 \%$, and $75 \%$ for $\mathrm{I}^{2}$ represent low, medium, and high heterogeneity, respectively (31). The result will be presented using a forest plot. If necessary, subgroup 
analysis will be performed, which will be based on possible factors that may lead to heterogeneity, such as intervention, control, age, treatment duration, and the quality of the study.

If the data are considered inadequate to be analyzed quantitatively, a systematic narrative synthesis will be performed to present the studies included in the review.

\section{Quality of certainty of evidence}

The Grading of Recommendations Assessment, Development and Evaluation (GRADE) classification will be used to assess the certainty of the evidence (32). This assessment classifies the evidence into four levels: very low, low, moderate, or high and will be performed individually by two reviewers, while a third reviewer will be invited should there be any divergence.

\section{Discussion}

Given the proportion of pregnant women affected by nausea and vomiting and the great impact on their quality of life, effective treatment options with minimal adverse effects must be available for these women. The ICPs have been conjectured as being potentially able to meet this demand, in addition to being inexpensive. However, there is no study available so far that widely verifies and gathers the available evidence on the subject. In light of the above, this study aimed to address this gap, to possibly assist in evidence-based practices provided to pregnant women who suffer from nausea and vomiting. It should be noted that there are limitations to this study, since there may not be enough evidence for a robust conclusion, but if this happens to be the case, a gap for further research will be highlighted. Also, an increased risk of bias may occur due to the heterogeneity of the ICPs, different methods, and sample sizes of the included studies.

\section{Abbreviations}

CENTRAL - Cochrane Central Register of Controlled Trials

CINAHL - Cumulative Index to Nursing and Allied Health Literature

CNKI - China National Knowledge Infrastructure

COS - Core Outcome Sets

CUMED - Cuban National Center for Information on Medical Sciences

IBECS - Índice Bibliográfico Español en Ciencias de la Salud

ICTRP - World Health Organization International Clinical Trials Registry Platform

GA - Gestational age

LILACS - Literatura Latino-americana em Ciências da Saúde 
Medline - Medical Literature Analysis and Retrieval System Online

ICPS - Integrative and Complementary Practices

PRISMA-P - Preferred Reporting Items for Systematic review and Meta-Analysis Protocols

PROSPERO - International Prospective Register of Systematic Reviews

ReBEC - Brazilian Registry of Clinical Trials

\section{Declarations}

\section{Ethical approval and consent to participate}

Not applicable.

\section{Consent for publication}

Not applicable.

\section{Availability of data and materials}

All data generated or analyzed during this study are included in this published article [and its supplemental information files].

\section{Competing interests}

The authors declare that they have no conflicting interests.

\section{Funding}

Not applicable.

\section{Authors' contributions}

MSN, PMR, ICPC, and CCM were involved in the conception, design, and refinement of methodological matters. MSN elaborated this paper, which was followed up by all the authors, so that they reviewed it, provided critical feedback on it, and approved the final version of this protocol.

\section{Acknowledgements}

Not applicable.

Authors' information 
Melissa Santos Nassif, Nursing School, Federal University of Alfenas-MG, Gabriel Monteiro da Silva street, 700-Centro, Alfenas, MG, 30.130-100, Brazil. E-mail: melissasantosnassif@hotmail.com

Isabelle Cristinne Pinto Costa, Nursing School, Federal University of Alfenas-MG, Gabriel Monteiro da Silva street, 700-Centro, Alfenas, MG, 30.130-100, Brazil. E-mail: isabelle.costa@unifal-mg.edu.br

Caroline de Castro Moura, Department of Medicine and Nursing, Federal University of Viçosa -MG, Peter Henry Rolfs avenue, Viçosa, MG, 36570-900, Brazil. E-mail: carol_castro_m@hotmail.com

Patrícia Mônica Ribeiro, Nursing School, Federal University of Alfenas-MG, Gabriel Monteiro da Silva street, 700-Centro, Alfenas, MG, 30.130-100, Brazil. E-mail: patricia.ribeiro@unifal-mg.edu.br

\section{References}

1. Koren G, Boskovic R, Hard M, Maltepe C, Navioz Y, Einarson A. Motherisk-PUQE (pregnancy-unique quantification of emesis and nausea) scoring system for nausea and vomiting of pregnancy. Am J Obstet Gynecol. 2002 May;186(5 Suppl Understanding):S228-31. doi: 10.1067/mob.2002.123054. PMID: 12011891..

2. Kjeldgaard HK, Vikanes Å, Benth JŠ, Junge C, Garthus-Niegel S, Eberhard-Gran M. The association between the degree of nausea in pregnancy and subsequent posttraumatic stress. Arch Womens Ment Health. 2019 Aug;22(4):493-501. doi: 10.1007/s00737-018-0909-z. Epub 2018 Sep 17. PMID: 30225528; PMCID: PMC6647437.

3. Van den Heuvel E, Goossens M, Vanderhaegen H, Sun HX, Buntinx F. Effect of acustimulation on nausea and vomiting and on hyperemesis in pregnancy: a systematic review of Western and Chinese literature. BMC Complement Altern Med. 2016 Jan 13;16:13. doi: 10.1186/s12906-016-0985-4. PMID: 26758211; PMCID: PMC4711053.

4. O'Donnell A, McParlin C, Robson SC, Beyer F, Moloney E, Bryant A, Bradley J, Muirhead C, NelsonPiercy C, Newbury-Birch D, Norman J, Simpson E, Swallow B, Yates L, Vale L. Treatments for hyperemesis gravidarum and nausea and vomiting in pregnancy: a systematic review and economic assessment. Health Technol Assess. 2016 Oct;20(74):1-268. doi: 10.3310/hta20740. PMID: $27731292 ;$ PMCID: PMC5075747.

5. Fejzo MS, Trovik J, Grooten IJ, Sridharan K, Roseboom TJ, Vikanes Å, Painter RC, Mullin PM. Nausea and vomiting of pregnancy and hyperemesis gravidarum. Nat Rev Dis Primers. 2019 Sep 12;5(1):62. doi: 10.1038/s41572-019-0110-3. PMID: 31515515.

6. Brasil. Ministério da Saúde. Secretaria de Atenção à Saúde. Departamento de Atenção Básica. Atenção ao pré-natal de baixo risco [recurso eletrônico] / Ministério da Saúde. Secretaria de Atenção à Saúde. Departamento de Atenção Básica. - 1. ed. rev. - Brasília : Editora do Ministério da Saúde, 2013

7. Fahimi F, Hrgovic I, El-Safadi S, Münstedt K. Complementary and alternative medicine in obstetrics: a survey from Iran. Arch Gynecol Obstet. 2011 Aug;284(2):361-4. doi: 10.1007/s00404-010-1641-8. 
Epub 2010 Aug 21. PMID: 20730543.

8. Kramer J, Bowen A, Stewart N, Muhajarine N. Nausea and vomiting of pregnancy: prevalence, severity and relation to psychosocial health. MCN Am J Matern Child Nurs. 2013 Jan-Feb;38(1):21-7. doi: 10.1097/NMC.0b013e3182748489. PMID: 23232775.

9. Attard CL, Kohli MA, Coleman S, Bradley C, Hux M, Atanackovic G, Torrance GW. The burden of illness of severe nausea and vomiting of pregnancy in the United States. Am J Obstet Gynecol. 2002 May;186(5 Suppl Understanding):S220-7. doi: 10.1067/mob.2002.122605. PMID: 12011890.

10. Smith C, Crowther C, Beilby J, Dandeaux J. The impact of nausea and vomiting on women: a burden of early pregnancy. Aust N Z J Obstet Gynaecol. 2000 Nov;40(4):397-401. doi: 10.1111/j.1479828x.2000.tb01167.x. PMID: 11194422.

11. Gadsby R, Rawson V, Dziadulewicz E, Rousseau B, Collings $H$. Nausea and vomiting of pregnancy and resource implications: the NVP Impact Study. Br J Gen Pract. 2019 Mar;69(680):e217-e223. doi: 10.3399/bjgp18X700745. Epub 2018 Dec 17. PMID: 30559108; PMCID: PMC6400600.

12. Garcia Saborio OE, Hines BK, Wesselman J. Safe Management of Nausea and Vomiting During Pregnancy in the Emergency Department. Adv Emerg Nurs J. 2019 Oct/Dec;41(4):336-347. doi: 10.1097/TME.0000000000000258. PMID: 31687998.

13. P. Chittumma, K. Kaewkiattikun, B. Wiriyasiriwach. Comparison of the effectiveness of ginger and vitamin B6 for treatment of nausea and vomiting in early pregnancy: a randomized double-blind controlled Trial. J. Med. Assoc. Thail., 90 (1) (2007), p. 15

14. Peprah P, Agyemang-Duah W, Arthur-Holmes F, Budu HI, Abalo EM, Okwei R, Nyonyo J. 'We are nothing without herbs': a story of herbal remedies use during pregnancy in rural Ghana. BMC Complement Altern Med. 2019 Mar 15;19(1):65. doi: 10.1186/s12906-019-2476-x. PMID: 30876425; PMCID: PMC6419816.

15. Lacasse A, Rey E, Ferreira E, Morin C, Bérard A. Validity of a modified Pregnancy-Unique Quantification of Emesis and Nausea (PUQE) scoring index to assess severity of nausea and vomiting of pregnancy. Am J Obstet Gynecol 2008; 198: 71. e1-71. e7.

16. Schürger, N., Klein, E., Hapfelmeier, A. et al. Demand for integrative medicine among women in pregnancy and childbed: a German survey on patients' needs. BMC Complement Altern Med18, 187 (2018). https://doi-org.ez37.periodicos.capes.gov.br/10.1186/s12906-018-2249-y.

17. Williams H, Sweet L, Graham K. Acupuncture during pregnancy and the perinatal period: Women's attitudes, beliefs and practices. Women Birth. 2020;33(3):e286-e294.

doi:10.1016/j.wombi.2019.04.010

18. Saber M, Khanjani N, Zamanian M, Safinejad H, Shahinfar S, Borhani M. Use of Medicinal Plants and Synthetic Medicines by Pregnant Women in Kerman, Iran. Arch Iran Med. 2019 Jul 1;22(7):390-393. PMID: 31679382

19. Ozgoli G, Saei Ghare Naz M. Effects of Complementary Medicine on Nausea and Vomiting in Pregnancy: A Systematic Review. Int J Prev Med. 2018 Aug 30;9:75. doi: 10.4103/ijpvm.IJPVM_430_16. PMID: 30319738; PMCID: PMC6177529. 
20. Catsaros S, Wendland J. Hypnosis-based interventions during pregnancy and childbirth and their impact on women's childbirth experience: A systematic review. Midwifery. 2020 May;84:102666. doi: 10.1016/j.midw.2020.102666. Epub 2020 Feb 12. PMID: 32087396.

21. Boltman-Binkowski H. A systematic review: Are herbal and homeopathic remedies used during pregnancy safe? Curationis. 2016 Apr 13;39(1):1514. doi: 10.4102/curationis.v39i1.1514. PMID: $27246791 ;$ PMCID: PMC6091622.

22. Bacaro V, Benz F, Pappaccogli A, De Bartolo P, Johann AF, Palagini L, Lombardo C, Feige B, Riemann D, Baglioni C. Interventions for sleep problems during pregnancy: A systematic review. Sleep Med Rev. 2020 Apr;50:101234. doi: 10.1016/j.smrv.2019.101234. Epub 2019 Nov 14. PMID: 31801099.

23. Koukoulithras I Sr, Stamouli A, Kolokotsios S, Plexousakis M Sr, Mavrogiannopoulou C. The Effectiveness of Non-Pharmaceutical Interventions Upon Pregnancy-Related Low Back Pain: A Systematic Review and Meta-Analysis. Cureus. 2021 Jan 30;13(1):e13011. doi:

10.7759/cureus.13011. PMID: 33728108; PMCID: PMC7934802.

24. Corbijn van Willenswaard K, Lynn F, McNeill J, McQueen K, Dennis CL, Lobel M, Alderdice F. Music interventions to reduce stress and anxiety in pregnancy: a systematic review and meta-analysis. BMC Psychiatry. 2017 Jul 27;17(1):271. doi: 10.1186/s12888-017-1432-x. PMID: 28750631; PMCID: PMC5531014.

25. Sheffield KM, Woods-Giscombé CL. Efficacy, Feasibility, and Acceptability of Perinatal Yoga on Women's Mental Health and Well-Being: A Systematic Literature Review. J Holist Nurs. 2016 Mar;34(1):64-79. doi: 10.1177/0898010115577976. Epub 2015 Apr 20. PMID: 25896571; PMCID: PMC6739069.

26. Higgins JPT, Green S, editores. Cochrane Handbook for Systematic Reviews of Interventions Version 5.1.0 [atualizado em março de 2011]. Disponível em: The Cochrane Collaboration; 2011. https://training.cochrane.org/handbook .

27. Committee on Practice Bulletins-Obstetrics. ACOG Practice Bulletin No. 189: Nausea And Vomiting Of Pregnancy. Obstet Gynecol. 2018 Jan;131(1):e15-e30. doi: 10.1097/AOG.0000000000002456. PMID: 29266076.

28. McGlinchey MP, James J, McKevitt C, Douiri A, McLachlan S, Sackley CM. The effect of rehabilitation interventions on physical function and immobility-related complications in severe stroke-protocol for a systematic review. Syst Rev. 2018;7(1):197. Published 2018 Nov 17. doi:10.1186/s13643-0180870-y.

29. Sterne JAC, Savović J, Page MJ, Elbers RG, Blencowe NS, Boutron I, Cates CJ, Cheng HY, Corbett MS, Eldridge SM, Emberson JR, Hernán MA, Hopewell S, Hróbjartsson A, Junqueira DR, Jüni P, Kirkham JJ, Lasserson T, Li T, McAleenan A, Reeves BC, Shepperd S, Shrier I, Stewart LA, Tilling K, White IR, Whiting PF, Higgins JPT. RoB 2: a revised tool for assessing risk of bias in randomised trials. BMJ. 2019 Aug 28;366:I4898. doi: 10.1136/bmj.I4898. PMID: 31462531.

30. Lau J, loannidis JP, Schmid CH. Quantitative synthesis in systematic reviews. Ann Intern Med. 1997;127(9):820-6. 
31. Higgins JPT, Thompson SG. Quantifying heterogeneity in a meta-analysis. Statist Med. 2002;21:1539-58.

32. Guyatt GH, Oxman AD, Schunemann HJ, Tugwell P, Knottnerus A. Diretrizes GRADE: uma nova série de artigos no Journal of Clinical Epidemiology. J Clin Epidemiol. 2011. https://doi.org/10.1016/j.jclinepi.2010.09.011 .

\section{Supplementary Files}

This is a list of supplementary files associated with this preprint. Click to download.

- PRISMAPchecklist.docx 